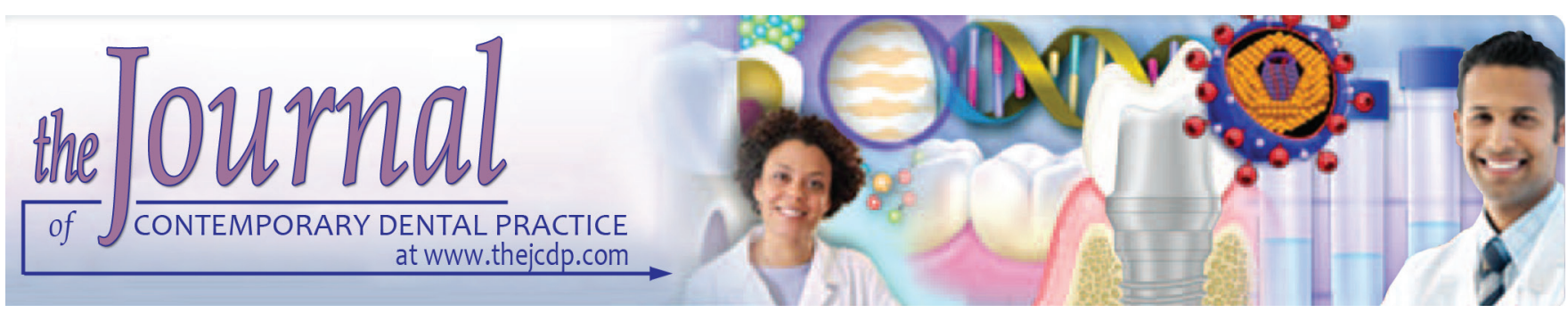

\title{
Dautrey's Procedure Revisited in Management of Recurrent Mandibular Dislocation
}

\author{
1Joanna Baptist, ${ }^{2}$ Mohan Baliga
}

\begin{abstract}
Introduction: Mandibular dislocation occurs when the condylar head glides out of the glenoid fossa with the condyle positioned in such a way that its posterior articulating surface lying ahead of the articular eminence. Recurrent mandibular dislocation is relatively uncommon. Patient is extremely distressed and goes through a lot of discomfort. Varied etiologies have been cited in the literature, such as keeping the mouth wide open for long periods of time during dental procedures, yawning, laughing, traumatic injuries to the mandible, psychiatric disturbances, and certain drugs. Acute dislocations are best managed immediately by reduction and intermaxillary fixation. However, dislocations that have remained over a period of a month are considered to be chronic and these cannot be reduced successfully by manual manipulation of the mandible.

Such chronic recurrent dislocations are surgically managed with eminectomy, meniscectomy, and condylotomies. A downward and forward osteotomy of the zygomatic arch in front of the articular eminence so as to produce a mechanical obstruction was recommended by Dautrey and Gosserez. This article will highlight the surgical experience of managing six patients with chronic recurrent dislocations of the temporomandibular joints (TMJs) bilaterally employing Dautrey's procedure.
\end{abstract}

Keywords: Condyle, Dautrey procedure, Mandibular dislocation, Recurrent.

How to cite this article: Baptist J, Baliga M. Dautrey's Procedure Revisited in Management of Recurrent Mandibular Dislocation. J Contemp Dent Pract 2017;18(1):78-79.

Source of support: Nil

Conflict of interest: None

\footnotetext{
1,2Department of Oral and Maxillofacial Surgery, Manipal College of Dental Sciences, Manipal University, Mangaluru, Karnataka India

Corresponding Author: Mohan Baliga, Department of Oral and Maxillofacial Surgery, Manipal College of Dental Sciences Manipal University, Mangaluru, Karnataka, India, e-mail: mohan. baliga@manipal.edu
}

\section{INTRODUCTION}

Temporomandibular joint (TMJ) is the most used and abused joint, causing a number of problems. ${ }^{1}$ Mandibular dislocation is one of the earliest disorders affecting jaws described in the literature. Hippocrates in 5 BC discussed the condition, and the reduction technique is still used to date. Incidence of mandibular dislocation is only $3 \%$, and recurrent dislocation is even more uncommon, which is a very distressing condition. ${ }^{2}$

In true dislocation, the condyle is displaced from its articulation and requires manipulation by a professional. Conservative treatment modalities for recurrent dislocations include intermaxillary fixation and injections of sclerosing solutions ${ }^{3}$ and autologous blood. ${ }^{4}$

Surgical techniques can be broadly classified into surgeries that limit the condylar path and those that enhance the condylar path. ${ }^{5}$ Most commonly used techniques are eminectomy described by Myrhaug (1951) and the zygomatic arch inferior down fracture as described by LeClerc and Girard in 1943, modified later by Gosserez and Dautrey (1967). ${ }^{1,5,6}$

In the original LeClerc and Girard technique, a vertical osteotomy of the zygomatic arch was performed in front of the joint and the proximal segment lowered to obstruct the condylar path. Gosserez and Dautrey popularized downward and forward osteotomy of the zygomatic arch in front of the articular eminence to create similar mechanical obstruction and recommended the procedure to be carried out bilaterally in all cases irrespective of either unilateral or bilateral dislocation. ${ }^{1,2,6}$

Six patients with bilateral chronic recurrent dislocation of the TMJ were managed with Dautrey's procedure. Bilateral procedures were performed on all patients. Preauricular incision with temporal extension was used and skin flap was raised along temporal fascia (Fig. 1). An oblique incision parallel to the branches of facial nerve was made on periosteum over the zygomatic 


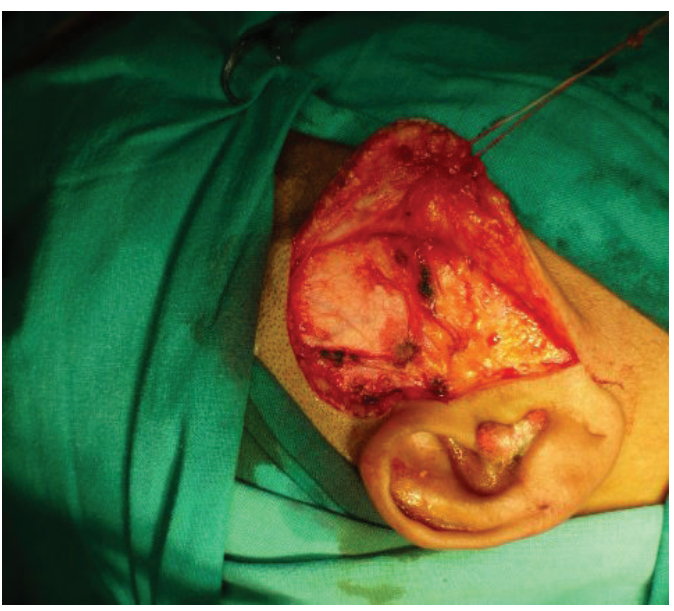

Fig. 1: Preauricular incision with temporal extension

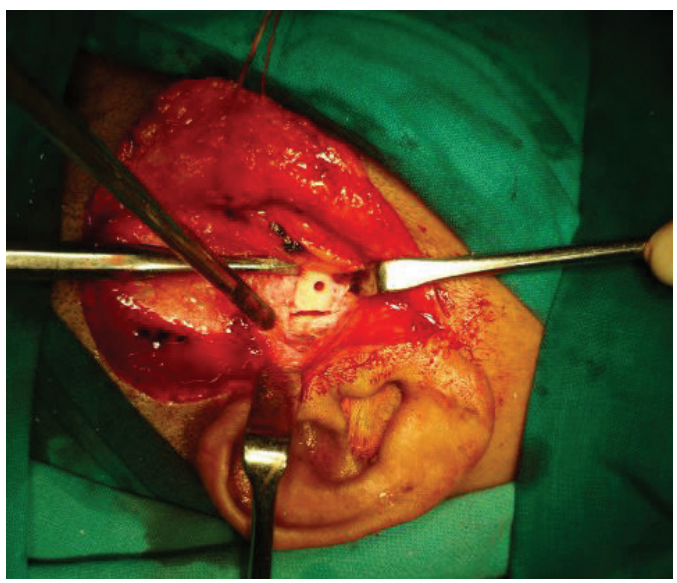

Fig. 3: Minimal downward and forward oblique osteotomy of the arch

arch (Fig. 2). Posterior aspect of the arch was exposed, keeping the periosteum attached anteriorly.

A minimal downward and forward oblique osteotomy of the arch was made (Fig. 3). A bur hole each was made on proximal and distal segment of the zygomatic arch. A 26 gauge wire was passed through the bur hole created in the proximal segment and controlled pressure was used to fracture the proximal segment of the arch which was then brought below the distal segment. A 26 gauge wire was used to fix the displaced arch in position (Fig. 4). Surgical incision was closed in layers. No intermaxillary fixation was used postoperatively and all patients tolerated soft diet a day after the procedure. Short operating time and less invasiveness are the advantages of this procedure. ${ }^{3}$ Also, it does not disturb the internal structure of the joint, thereby maintaining its physiology. A 2- to 6-year follow-up of our patients have not experienced any episodes of dislocation postoperatively.

Original Dautrey procedure was used without fixation. Revington reasoned that small condylar heads are able to pass anteromedial to the repositioned arch causing recurrence. Poirier et al used mini plates for fixation to

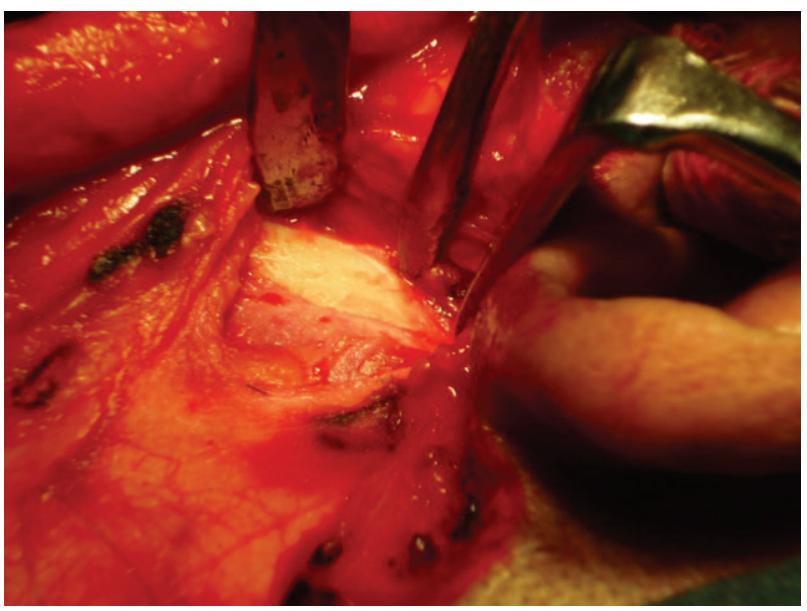

Fig. 2: Exposure of zygomatic arch

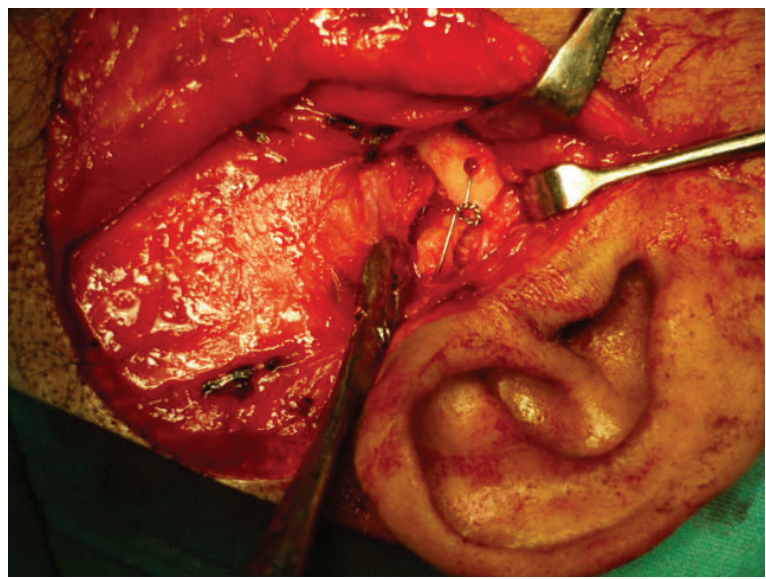

Fig. 4: Twenty six gauge wire used to fix the displaced arch in position

avoid this. ${ }^{1}$ We believe wire fixations provide enough rigidity to retain the position of the osteotomized arch, hence reducing the risk of recurrence.

\section{REFERENCES}

1. Gadre KS, Kaul D, Ramanojam S, Shah S. Dautrey's procedure in treatment of recurrent dislocation of the mandible. J Oral Maxillofac Surg 2010 Aug;68(8):2021-2024.

2. Merrill, Ralph G. Mandibular dislocation in surgery of the temporomandibular joint. 2nd ed. Keith, DA, editor. Blackwell Scientific Publications; 1992. p. 154-179.

3. Kobayashi H, Yamazaki T, Okudera H. Correction of recurrent dislocation of the mandible in elderly patients by the Dautrey procedure. Br J Oral Maxillofac Surg 2000 Feb;38(1):54-57.

4. Hegab AF. Treatment of chronic recurrent dislocation of the temporomandibular joint with injection of autologous blood alone, intermaxillary fixation alone, or both together: a prospective, randomised, controlled clinical trial. Br J Oral Maxillofac Surg 2013 Dec;51(8):813-817.

5. Caminiti MF, Weinberg S. Chronic mandibular dislocation: the role of non-surgical and surgical treatment. J Can Dent Assoc 1998 Jul-Aug;64(7):484-491.

6. Srivastava D, Rajadnya M, Chaudhary MK, Srivastava JL. The Dautrey procedure in recurrent dislocation: a review of 12 cases. Int J Oral Maxillofac Surg 1994 Aug;23(4):229-231. 